Sādhanā Vol. 39, Part 4, August 2014, pp. 819-841. (C) Indian Academy of Sciences

\title{
Optimal sizing of energy storage system for microgrids
}

\author{
BABAK MOZAFARI $^{1}$ and SIRUS MOHAMMADI ${ }^{2, *}$ \\ ${ }^{1}$ Department of Electrical Engineering, Science and Research Branch, Islamic Azad \\ University, Tehran 14778-93855, Iran \\ ${ }^{2}$ Department of Engineering, College of Electrical Engineering, Yasouj Science and \\ Research Branch, Islamic Azad University, Yasouj 73517-64834, Iran \\ e-mail: s.mohammadi@ srbiau.ac.ir
}

MS received 6 October 2012; revised 19 March 2014; accepted 26 March 2014

\begin{abstract}
Microgrids (MGs) are Low Voltage distribution networks comprising various distributed generators (DG), storage devices and controllable loads that can operate either interconnected or isolated from the main distribution grid as a controlled entity. Energy storage system (ESS) is a vital part of an MG. In this paper, a methodology is proposed for the optimal allocation and economic analysis of ESS in MGs on the basis of net present value (NPV). As the optimal operation of an MG strongly depends on the arrangement and allocation of its ESS, economic operation strategies and optimal allocation methods of the ESS devices are required for the MG. Self-adaptive Bee Swarm Optimization (SBSO) algorithm is applied to optimize the operation strategies and capacities of ESS in MGs in order to find maximal NPV, the generation schedule of ESS and distributed generation sources. This paper is to suggest, among those available ESS, the optimal sizes and types of them and their optimal arrangement, such that the total NPV achieved during the system operational lifetime period is maximized. After introducing the methodology, a case study is presented for illustration.
\end{abstract}

Keywords. Microgrid; energy storage system; optimal sizing; net present value.

\section{Introduction}

Renewable energy is currently widely used. Due to the intermittent nature of renewable energy sources and the continuous variations of the load, storage (e.g., battery, ultra capacitor, flywheel, etc.) is usually needed in a renewable powered Microgrid (MG). The renewable output power profile and the load profile are two important factors in deciding the capacity and type of the energy storage components. The MG can either be connected to the main grid or work autonomously with respect to the grid-connected mode or islanded mode, respectively. For gridconnected MGs, the upstream grid can support power to the MG during the peak load period. The extra power generated by renewable energy generators during the low load period can be sold

${ }^{*}$ For correspondence 
back to the upstream grid. Market prices need to be considered in this mode and the objective function is to maximize the market profit.

Optimal allocation and economic evaluation of ESS always poses a complex problem because of its inter-temporal nature, i.e., the operation of the ESS in one time step will affect its operation in the others. Allocation of ESS is to be considered first when considering storage in the MG. Some research works have been done to address this question. A two-stage stochastic optimization problem was proposed by Abbey \& Joós (2009) to address the problem of ESS allocation and sizing for isolated wind-diesel power systems, with the objective of minimizing the cost of the energy supplied. Both operational costs and fixed costs were incorporated into the formulation of the optimization problem by Garcia \& Weisser (2006). From another perspective, Poonpun \& Jewell (2008) presented an interesting technique for a simple economic feasibility evaluation of small energy storage facilities. The technique calculated the cost added to each kilowatt hour of energy that is stored and later returned to the grid. An optimal participation strategy is presented by Dukpa et al (2010) for the wind electric generators that employ an energy storage device for participating in the day-ahead unit commitment process. Berkeley Lab's DER-CAM is presented to evaluate combined heat and power opportunities since it selects the optimal combination of DER and storage investment options, fully taking their interdependence into account (Marnay et al 2008). Chen et al (2012) employ a cost-benefit analytical technique to estimate the economic feasibility of the ESS deployment for both the grid-connected and islanded modes.

Another reference covers some design and operation aspects of distributed battery microstorage systems in a deregulated electricity market system (Ala et al 2012). The term 'micro' refers to the size of the energy storage system compared to the grid generation, with a capacity from few kilowatt-hours and up. Generally, ES enhances the performance of renewable distributed generators (DGs) and increases the efficiency of the entire power system. Energy storage allows for leveling the load, Peak Shaving demands and furthermore, transacting power with the utility grid.

Duong \& Ashwin (2013) presented an energy manager for energy storage system in microgrids. The objectives of the energy manager are focused on improving the energy efficiency and extending the life expectancy of ESS while ensuring constraints of energy storage modules are complied with.

Optimal design is carried out by means of minimum capital and management cost formulations and does not typically consider optimized operation. A generalized double-shell framework for the optimal design of systems managed optimally according to different criteria is developed (Maria Luisa et al 2014). In this reference, the optimized multiobjective management is explicitly considered into the design formulation. The quality of each design solution is indeed defined by the evaluation of operational costs and capital costs.

Mohammadi et al (2014a, b) presented a unit commitment formulation for micro-grid that includes a significant number of grid parallel Proton Exchange Membrane-Fuel Cell Power Plants (PEM-FCPPs) with ramping rate and minimum up/down time constraints. The aim of this problem is to determine the optimum size of energy storage like battery storages and use the efficient hydrogen and thermal energy storages and to schedule the committed units' output power while satisfying practical constraints and electrical/thermal load demand over one day with 15 min time step. Due to uncertainty nature of electrical/thermal load, photovoltaic and wind turbine output power and market price, a two-stage scenario-based stochastic programming model, where the first stage prescribes the here-and-now variables and the second stage determines the optima value of wait-and-see variables under cost minimization is implemented. 
Zhen \& Panida (2014) proposed an adaptive optimal policy for hourly operation of an energy storage system in a grid connected wind power company. The purpose was to time shift wind energy to maximize the expected daily profit following uncertainties in wind generation and electricity price. A stochastic dynamic programming (SDP) framework was adopted to formulate this problem, and an objective function approximation method was applied to improve the SDP computational efficiency.

A probabilistic energy management system to optimize the operation of the micro-grid based on an efficient Point Estimate Method is proposed (Mohammadi et al 2013). This method was used to model the uncertainty in the power generation of the wind farms and the Photovoltaic systems, the market prices and the load demands. A unit commitment formulation for micro-grid that includes a significant number of grid parallel PEM-Fuel Cell Power Plants with ramping rate and minimum up and down time constraints. The aim of this problem is to determine the optimum size of energy storage devices like hydrogen, thermal energy and battery energy storages in order to schedule the committed units' output power while satisfying practical constraints and electrical/thermal load demand over one day with 15 min time step (Mohammadi et al 2014a, b).

From the above survey, a common drawback of the ESS design methods is that the proposed methods only take into account one or more aspects, rather than the comprehensive design aspects, which can extremely influence the total economic benefits achieved, such as the operational and economical interdependence between various energy storage devices and charge/discharge control systems, the peak power, the maximum/minimum storable energy of energy storage installation and the equality constraint of the periodical behaviour. This paper focuses on a new approach for optimal allocation and economic operation of ESS in MGs using SBSO algorithm with consideration of the comprehensive design aspects. The quality of the optimization is estimated according to the NPV in different conditions.

\section{Operation principle and policy of MGs}

The optimal integration of ESS in MGs is dependent on configuration of the MG, operation scheme, power balancing and policy of power exchange at inverter capacity shortage (Changsong et al 2011).

MG is a new type of power systems consisting of generation sources, loads and energy storages. Micro Turbine (MT), renewable energy sources like solar and wind can be interfaced through the distributed power generation modules with the MG system, which can operate in islanded mode (off-grid) and grid-connected mode. The MG operation needs to respond to the load demand under any circumstances; therefore, backup with energy storage elements is essential. The size and type of the storages are determined by system's requirements. In this paper, it is assumed that the system works in grid-connected mode. According to this mode, the MG tries to maximize the revenues of the aggregator by exchanging power with the grid. The exchange procedure as follows: every day, each DG source bids for the production for the next day in $1 \mathrm{~h}$ intervals. The MG optimizes its operation according to the open market prices, the forecasted loads and the bids of the DG sources. In addition, consumers within the MG might bid for their loads supply for the next day in the same 1-h intervals. In this case, the MG optimizes the operation based on DG sources and load bids. Moreover, it is assumed that the MG has sufficient capacity to satisfy the demand of its local customers. Therefore, the MG operation for balancing the supply and demand can be executed individually in every interval. It is assumed that each DG source places bids reflecting its priorities. The bids are determined according to their operating and maintenance costs, capital costs, and energy purchase costs. In this case, if the capacity 
of the MG were surplus, 'Low' priority DG sources would be shed according to the pre-defined order of priorities.

Two operational procedures are considered and compared in this paper.

(i) Prioritized capacity allocation for real power: In this step, allocation of the inverter capacity for active power is given priority over reactive power.

$$
\begin{gathered}
p_{i n v_{-} \lim }=S_{i n v_{-} \lim }, \\
q_{i n v_{-} \lim }=\sqrt{S_{i n v_{-} \lim }^{2}-p_{i n v}^{2}} .
\end{gathered}
$$

(ii) Prioritized capacity allocation for reactive power: Conversely, for this procedure, allocation of the inverter capacity for reactive power is given priority over active power

$$
\begin{gathered}
q_{i n v_{-} \lim }=S_{i n v_{-} \lim }, \\
p_{i n v_{-} \lim }=\sqrt{S_{i n v_{-} \lim }^{2}-q_{i n v}^{2}} .
\end{gathered}
$$

As is well-known, the amount of solar generated by renewable energy sources depend on sunshine, temperature and the climatic conditions on site. Time series and feed-forward neural network techniques are used for forecasting the solar radiations (Taylor et al 2009).

\section{Energy storage systems}

In recent years, several forms of energy storage are studied intensely. These include electrochemical battery, compressed air energy storage, superconducting magnetic energy storage, supercapacitor and flywheel energy storage. Energy stored in the storage device is expressed as follows.

- Charge $(p(t)<0)$ :

$$
\begin{gathered}
-\eta_{c} p(t) \Delta t \leq k_{c} c_{\max } \\
c(t+1)=c(t)-\eta_{c} p(t) \Delta t
\end{gathered}
$$

- Discharge $(p(t)>0)$ :

$$
\begin{gathered}
\frac{p(t) \Delta t}{\eta_{D}} \leq K_{D} c_{\max } \\
c(t+1)=c(t)-p(t) \Delta t / \eta_{D}
\end{gathered}
$$

- Idle $(p(t)=0)$ :

$$
c(t+1)=c(t)-W_{\text {hourly }} .
$$

Consumers are assumed to be charged at the open market prices for grid-connected MGs. When the market prices are high, ESS can discharge more power to serve the local load, without buying high-priced energy from grid. In the low prices, it is beneficial for the ESS to absorb the lowpriced energy. However, when there are many ESS and DG sources in a MG, it is very difficult to schedule the optimal DG/ESS outputs to maximize the NPV. 


\section{Economical analysis}

Whenever there are different investment schemes with either different technologies or different scales for a MG, technical and economic quantitative analysis should be carried out and economic assessment should be given in order to select the optimal scheme. In order to start an economical analysis, one must consider the ESS and DG capital costs, Replacement Cost, operating and maintenance costs, energy purchase costs, etc. In order to make the analysis simpler, it is supposed that all the units work in electricity mode and no heat are needed. The electrical efficiency of the fuel-consuming units, as well as the depreciation time, has been taken into account.

\subsection{Capital cost}

Eq. 10 gives the factor of capital recovery, which is an important factor in economic analysis and abbreviated as CRF (capital recovery factor).

$$
C R F=\frac{i(1+i)^{n}}{(1+i)^{n}-1}
$$

where $i$ is the interest rate and $n$ is the depreciation period in years.

The capital cost of ESS is defined as a function of two main parts: (i) The storable energy. (ii) The peak power that the storage must deliver.

Then, the capital cost per day (CCPD) of ESS can be found in (11)

$$
C C P D^{E S S}=\frac{24}{k_{i} \cdot T_{a}} \times \frac{i(1+i)^{n}}{(1+i)^{n}-1}\left(S C_{p} P_{M}+S C_{W} W_{M}\right),
$$

where $P_{M}(\mathrm{~kW})$ is energy storage system power and $W_{M}(\mathrm{kWh})$ is energy capacity, $S C_{p}(\$ / \mathrm{kW})$ and $S C_{W}(\$ / \mathrm{kWh})$ are their specific costs, 24 is the number of hours of a day, $k_{i}$ is the capacity factor.

Therefore, the capital cost per day (CCPD) for DG is shown in (12)

$$
C C P D^{D G}=\frac{24}{k_{i} \cdot T_{a}} \times \frac{i(1+i)^{n}}{(1+i)^{n}-1} \sum_{s=1}^{l} C C_{s}^{D G} R_{s}
$$

where $C C_{s}^{D G}$ is the capital cost of $s$ th DG, $R_{S}$ is the installed capacity of $s$ th DG.

\subsection{Operating and maintenance cost}

The operating and maintenance cost of DG may be specified in \$/hour. Therefore, Operating and maintenance cost for a DG in a time period can be calculated by multiplying operating and maintenance cost of DG with operating hours. The operating and maintenance (OM) cost per day of DG can be obtained in (13)

$$
O M^{E S S}=\sum_{s=1}^{l} O M_{s} \cdot R_{s} \cdot 24
$$

Energy storage hourly operating and maintenance cost is defined as a function of two major parts: (i) The ESS rated power. (ii) Hourly discharged energy. 
The hourly operating and maintenance cost of ESS will be expressed as

$$
O M^{D G}=\sum_{P(t) \neq 0, t=1,2, \ldots, 24} S C_{O} P_{M}+\sum_{P(t)=0, t=1,2, \ldots, 24} S C_{M} W_{\text {hourly }} .
$$

\subsection{Replacement cost}

Replacement cost (RC) of a DG originates because the component lifetime can be different from the project lifetime (Agalgaonkar et al 2006). Replacement cost of DG can be obtained in (15)

$$
R C^{D G}=\frac{24}{k_{i} \cdot T_{a}}\left(\sum_{s=1}^{l} R C_{S}^{D G} \cdot R_{s} \cdot R F_{s} \cdot S F F\left(i, L_{s}^{D G}\right)-\sum_{s=1}^{l} S_{S} \cdot \operatorname{SFF}\left(s, L_{p r o j}\right)\right)
$$

where $R C_{S}^{D G}$ is the replacement cost of $s$ th DG, $R F_{s}$ is the replacement factor of $s$ th DG, $S s$ is the salvage value of $s$ th DG, $S F F\left(s, L_{\text {proj }}\right)$ is the sinking fund factor, $L_{s}^{D G}$ is the lifetime of $s$ th DG, and $L_{\text {proj }}$ is the lifetime of project.

$\mathrm{RC}$ of ESS can be obtained in (16)

$$
\begin{aligned}
R C^{E S S}=\frac{24}{k_{i} \cdot T_{a}}\left(\sum_{S=1}^{l}\left(R C_{P} \cdot P_{M}+R C_{W} \cdot W_{M}\right) R F^{B A T}\right. \\
\left.\quad \times S S F\left(i, L^{B A T}\right)-\sum_{s=1}^{l} S^{B A T} \cdot S F F\left(i, L_{p r o j}\right)\right),
\end{aligned}
$$

where $R C_{W}(\$ / \mathrm{kWh})$ is the replacement cost of ESS energy capacity, $R C_{P}(\$ / \mathrm{kW})$ is the replacement cost of ESS power capacity, $R F^{B A T}$ is the replacement factor of ESS, $L^{B A T}$ is the lifetime of ESS, and $S^{B A T}$ is the salvage value of ESS.

\subsection{Start-up cost}

Start-up cost (SC) is considered just for fuel-consuming units. For the MT, the fuel cost for the start-up period at full capacity and half of its efficiency has been taken into account to calculate the start-up cost. For the FC, the start-up cost considered is defined as a function of two major parts: (i) The hot start-up cost. (ii) The cold start-up cost.

To simplify our analysis, for this kind of generators the fuel consumed is defined as

$$
S C^{D G}=\sum_{s=1}^{l} S C_{S}^{D G} \times N_{s}
$$

where $S C_{S}^{D G}$ is the start-up cost of $s$ th DG, $N_{s}$ is the number of start-up.

\subsection{Fuel cost}

For fuel-powered generators, it is assumed that fuel prices of fuel-powered generators are different according to the operation date. The fuel cost (FC) is defined as

$$
F C^{D G}(d)=\sum_{s=1}^{r} \sum_{t=1}^{24} F P_{S}^{D G}(d) \times A_{s}(t),
$$


where $F P_{S}^{D G}$ (\$/unit fuel) is the fuel price of $s$ th DG on day $d, A_{s}(t)$ is the fuel utilized by $s$ th DG at hour $t$, and $r$ is the number of fuel-consuming DG.

\subsection{Revenue from selling power to upstream network}

The MG participates in the open market, buying and selling power to the grid. Charges are improved by selling power to the grid over a period of one day. The tax will be charged when MGs sell power to the grid. The revenue could be defined as

$$
R E^{D G}=\left(1-S_{t}\right) \sum_{s=1}^{l} \sum_{t=1}^{24} E P(t) E_{s}(t) .
$$

$E P(t)(\$ / \mathrm{kWh})$ is the energy price at hour $t, E_{S}(t)(\mathrm{kWh})$ is the energy sell to grid of $s$ th DG, and $S_{t}$ is the tax rate and is assumed to be $10 \%$.

For grid-connected MGs, the upstream grid can support power to the MG during the peak load period. The extra power generated by renewable energy generators during the low load period can be stored and sold back to the upstream grid during peak load level. Market prices need to be considered in this mode and the objective function is to maximize the market profit.

The ESS purchase cost (PC) and the revenue of its production power (RPP) can be defined as

$$
\begin{gathered}
P C^{B A T}=\sum_{P(t)<0, t=1, \ldots, 24} E P(t) \cdot p(t) *(1 h), \\
R P P^{B A T}=\left(1-S_{t}\right) \sum_{P(t)>0, t=1, \ldots, 24} E P(t) \cdot p(t) *(1 h) .
\end{gathered}
$$

The daily benefit (DB) under this operation is

$$
D B^{B A T}=P C^{B A T}+R P P^{B A T} .
$$

Benefits can be made only if ESS efficiency is greater than the ratio (off-peak energy price/peak energy price).

The following equation and constraint must be considered

- State of charge limits is given by

$$
\left\{\begin{array}{l}
C_{\min } \leq C(t) \leq C_{\max } \\
C(0)=C_{I}(\text { initial }- \text { state }) \\
C(t)=C_{F}(\text { final }- \text { state })
\end{array}\right.
$$

- Output power limits

Discharge $(p(t)>0)$

$$
p_{l}(t)=\min \left(\eta_{D}\left(C(t-1)-C_{\min }\right), \eta_{D} K_{D} C_{\max }\right)
$$

Charge $(p(t)<0)$ :

$$
p_{l}(t)=\max \left(\frac{\left(C_{\max }-C(t-1)\right)}{\eta_{C}}, \frac{K_{C} C_{\max }}{\eta_{C}}\right) .
$$


The equality constraint of the ESS periodical behaviour:

$$
\left\{\begin{array}{l}
C(0)=C_{I}=C(t)=C_{F} \\
\frac{1}{\eta_{D}} \sum_{P(t)>0, t=1, \ldots, 24} p(t)+\eta_{C} \sum_{P(t)<0, t=1, \ldots, 24} p(t)+\sum_{P(t)=0, t=1, \ldots, 24} W_{\text {hourly }}=0 .
\end{array}\right.
$$

\subsection{Net present value (NVP)}

The NPV in an engineering project is the difference between the present values of the total profit and total cost of the project within its operational lifetime. Obviously, the higher the net present value is, the higher is the economic benefit. The ESS can be managed to decrease the operating cost by storing low-price energy during light-load periods and then selling it to grid or delivering it to load during peak-load ones. The operating cost (OC) of the MG with storage within a period of one day is as follows:

$$
\begin{aligned}
O C= & C C P D^{D G}+O M^{D G}+R C^{D G}+S C^{D G}+F C^{D G}(d)-R E^{D G} \\
& +C C P D^{E S S}+O M^{E S S}+R C^{E S S}-D B^{B A T} .
\end{aligned}
$$

The operating cost without ESS within a period of one day is defined as

$$
O C^{*}=C C P D^{D G}+O M^{D G}+R C^{D G}+S C^{D G *}+F C^{D G *}(d)-R E^{D G *},
$$

where

$$
\begin{gathered}
S C^{D G *}=\sum_{s=1}^{l} S C_{S}^{D G} \times N_{s}^{*}, \\
F C^{D G *}(d)=\sum_{s=1}^{r} \sum_{t=1}^{24} F P_{S}^{D G}(d) \times A_{s}^{*}(t), \\
R E^{D G *}=\left(1-S_{t}\right) \sum_{s=1}^{l} \sum_{t=1}^{24} E P(t) E_{s}^{*}(t) .
\end{gathered}
$$

The NPV of the system for all the daily costs obtained is calculated by

$$
N P V=O C^{*}-O C
$$

where $O C^{*}$ is operating cost without energy storage and $O C$ is operating cost with consideration energy storage in MG.

\section{Self-adaptive bee swarm optimization method}

\subsection{Overview of standard BSO}

In the BSO algorithm, the swarm of the bees consists of three groups, the forager, the onlooker and the scout bees. At each generation of the BSO algorithm, a few numbers of the bees with the worst fitness value are assigned as the scout bees. The scout bees walk randomly in a feasible space to find better solutions. The remaining bees are partitioned equally into two groups. The first group associated with the best fitness value is called the forager bees and the other half called the onlooker bees. 


\subsection{Self-adaptive learning mechanism}

In the original BSO, three groups of the bees with three different moving patterns exist in the swarm. The percentage of the bees in each group is defined by a trial-and-error approach and is constant in all generations. For several drawbacks with these three strategies, they are unable to provide satisfactory solutions in problems with different fitness landscape. For example, none of these three methods could make effective diversity in solutions. The BSO-RT suggests a technique to control the diversity of the solutions (Akbari et al 2010). In this technique, the scout bees walk randomly in a region with radius $\tau$, find new solutions and select the best one to replace their pervious solutions. In this approach, if each scout bee finds only one new solution the algorithm could not provide satisfactory diversity. On the other hand, as the number of the found solutions increases, the computational burden increases. In addition, the effectiveness of each considered updating strategy may change throughout the iterative procedure. To overcome the drawbacks associated with the original BSO algorithm and the other modified version of it, this paper proposes a self-adaptive BSO algorithm to give the users a black-box optimization tool for various optimization problems. For this purpose, the SBSO algorithm presents four different moving patterns and each bee according to a probability model chooses one of these moving patterns to update its solutions. The probability model is based on the ability of each updating method to provide solutions with better quality. Using this approach, the bees self-adaptively identify which one of the moving strategies is more deserved to focus for the problem in hand.

To implement the SBSO, at first the probability of each moving pattern is considered $\operatorname{prbptrn}_{i}=0.25,(i=1, \ldots, 4)$ and a parameter named accumulator is assigned for each moving strategies as $\operatorname{acum}_{i}=0,(i=1, \ldots, 4)$. In each iteration, the bees are sorted based on their fitness values, and a weight factor is allocated to them. The better solution gets the larger weight factor as:

$$
w_{j}=\frac{\log \left(N_{\text {swrm }}-j+1\right)}{\log (1)+\ldots+\log \left(N_{\text {swrm }}\right)} j=1, \ldots, N_{\text {swrm }},
$$

where the $N_{\text {swrm }}$ is the number of the bees in the sorted set of the swarm i.e., $j=1$ is the bee with best fitness value and the $j=N_{\text {swrm }}$ is the bee with the worst one. The accumulator of each moving pattern is updated as:

$$
S_{i}=S_{i}+w_{j j} \quad j j=1, \ldots, N_{\text {method }_{i}},
$$

where $w_{j j} j j=1, \ldots, N_{\text {method }_{i}}$ are the weight factors of the individuals in the set of the bees which select the $i^{\text {th }}$ updating method and $N_{\text {method }_{i}}$ is the number of them. The excitation probability is calculated as:

$$
\operatorname{Prbptrn}_{i}=(1-\alpha) \times \operatorname{prbptrn}_{i}+\alpha \times \frac{S_{i}}{\operatorname{Iter}_{\max }},(i=1, \ldots, 4),
$$

where $\alpha$ is a learning rate to control the learning speed in the SBSO algorithm and is considered equal to $\alpha=0.142$ in this study. Finally, the normalized probability values of the moving patterns are computed as following:

$$
\operatorname{prbptrn}_{i}=\operatorname{Prbptrn}_{i} /\left(\operatorname{Prbptr}_{1}+\ldots+\operatorname{Prbptr}_{4}\right) .
$$

At each generation, each bee chooses the $i^{t h}$ moving pattern by roulette wheel mechanism based on their probability values. 


\subsection{Proposed moving patterns}

Method 1: This method was proposed by Akbari et al (2010) for updating the solution of the forager bees. Throughout the iterated procedure, each bee remembers its own best position associated with the best personal fitness value defined by $X_{\text {best }, j}^{k, t}$. Using the first updating strategy the new solution is calculated as follows:

$$
X_{\text {new }, j}^{k, t}=X_{\text {old }, j}^{k, t}+w_{b} \times r_{b} \times\left(X_{\text {best }, j}^{k, t}-X_{\text {old }, j}^{k, t}\right)+w_{g} \times r_{g} \times\left(G_{\text {best }}^{k, t}-X_{\text {old }, j}^{k, t}\right)
$$

where $G_{b e s t}^{k, t}$ is the best source food discovered by the swarm so far, $r_{b}$ and $r_{g}$ are two random numbers with uniform distribution between 0 and $1, w_{b}$ and $w_{g}$ specify the importance of the social and cognitive information and are defined as following:

$$
\begin{aligned}
& w_{b}=w_{\text {bmax }}+\frac{w_{\text {bmax }}-w_{b \text { min }}}{\text { Iter }_{\max }} \times \text { Iter }, \\
& w_{g}=w_{g \text { min }}+\frac{w_{\text {gmax }}-w_{g \text { min }}}{\text { Iter }_{\text {max }}} \times \text { Iter },
\end{aligned}
$$

$r_{b}$ and $r_{g}$ are determined independently, but if one of these numbers be so large or small, a good balance between the global and the local search could not be achieved, so this study specifies these numbers dependently as following (Akbari et al 2010):

$$
X_{\text {new }, j}^{k, t}=X_{\text {old }, j}^{k, t}+w_{b} \times r_{b} \times\left(1-r_{g}\right) \times\left(X_{\text {best }, j}^{k, t}-X_{\text {old }, j}^{k, t}\right)+w_{g} \times r_{g} \times\left(1-r_{b}\right) \times\left(G_{\text {best }}^{k, t}-X_{\text {old }, j}^{k, t}\right) \text {. }
$$

Method 2: This method is the one used in the BSO algorithm for the onlooker bees. In this technique, each bee advertises the source food which discovers it in the dance floor after that, each of the bees which selects Method 2 for updating its solution, chooses one of the advertised source foods using a probability approach. The probability of the bees is calculated as:

$$
\operatorname{prob}_{j}=\frac{1 / F\left(\left(X_{j}^{t}\right)\right)}{\left.\sum_{\vartheta=1}^{N_{s w r m}}\left(1 / F\left(X_{\vartheta}^{t}\right)\right)\right)},
$$

where $F\left(X_{\vartheta}(t)\right)$ is the fitness value of the $\vartheta^{t h}$ bee. The selected bee called the elite bee is determined by roulette based on the calculated probability values. Finally the new solutions using Method 2 is obtained as:

$$
X_{n e w, j}^{k, t}=X_{o l d, j}^{k, t}+r \times w_{e} \times\left(X_{e}^{k, t}-X_{o l d, j}^{k, t}\right) .
$$

Method 3: This paper proposes a new efficient updating method in which the mean value of the swarm at timet $M(t)$, along with $G_{\text {best }}^{k, t}$ are employed to find better solutions.

$$
X_{n e w, j}^{k, t}=X_{\text {old }, j}^{k, t}+r \times\left(G_{\text {best }}^{k, t}-l \times M^{k, t}\right) .
$$

Method 4: The SBSO algorithm proposes this new updating strategy to employ the information found by the other members of the swarm more efficient. Using this approach helps the SBSO algorithm to escaping from local optima and premature convergence. In this approach, for the 
$j^{\text {th }}$ bee which selects Method 4, two bees are selected randomly as $m_{1} \neq m_{2} \neq j$ thereafter, the new source food is obtained as:

$$
\left\{\begin{array}{l}
\text { if } F\left(X_{m_{1}}\right) \leq F\left(X_{m_{2}}(t)\right) \text { then } X_{n e w, j}^{k, t}=X_{\text {old }, j}^{k, t}+r \times\left(X_{m_{1}}^{k, t}-X_{m_{2}}^{k, t}\right) \\
\text { else } \\
X_{n e w, j}^{k, t}=X_{o l d, j}^{k, t}+r \times\left(X_{m_{1}}^{k, t}-X_{m_{2}}^{k, t}\right)
\end{array}\right.
$$

\section{Solution methodology}

The procedure of the proposed method can be summarized in the following steps:

Step 1 : Select different types of DG sources.

Step 2 : Decide maximum generation capacity for each DG sources.

Step 3 : Give priority to the DG sources.

Step 4 : choose one of ESSs.

Step 5 : Select incremental step size for power and energy capacities of ESS.

Step 6 : Check the generated combinations for validity.

The main variables of the proposed method are the forecasting power output of photovoltaic (PV), power and energy capacities of ESS. The bids of the PVs are in general higher than other DG sources, owing to their expensive capital cost. But, the MG operator has the obligation to buy energy produced by an independent PVs power producer connected to his MG. Government subsidizes the energy by granting the price difference to the network operator (Johanna \& Till 2011). The priority of the DG sources is implemented by adjusting the bids of the DG sources. The priority of PV is given by granting the price difference to its bids. The bids of the PVs due to this operation can be defined as

$$
B D^{p v}=C C^{p v}+R C^{p v}+O M^{p v}-G A R N T^{p v} .
$$

The procedure for implementing the OM optimization algorithm for a MG can be summarized in the following steps:

Step 1: Setprbptrn $i=0.25,(i=1, \ldots, 4), \operatorname{acum}_{i}=0,(i=1, \ldots, 4), \alpha=0.142$ and forecast PV power output and read the day-by-day value of fuel prices, and set $s=1$.

Step 2: Randomly initialize the initial positions of the bees in the feasible range.

Step 3: Run SBSO algorithm to minimize the operating cost of the MG without ESS within the $s$ th day from Eq. (27).

Step 4: Choose one of ESSs.

Step 5: Choose a particular pair of power and energy capacities of the ESS.

Step 6: Run SBSO algorithm to minimize the operating cost of the MG with ESS using different pairs of power and energy capacities within the $s$ th day from Eq. (26).

Step 7: Calculate the NPV of the energy storage device from Eq. (31), and set $s=s+1$.

Step 8: Repeat step 3-7 until $s=365$.

Step 9: Find the maximum NPV of every day in a year and the index corresponding to the maximum NPV.

Step 10: Calculate the one-year NPV of the energy storage devices based on the previous results. 


\section{Simulation results}

A typical study case LV network, shown in figure 1, has been proposed by Tsikalakis \& Hatziargyriou (2008). The network comprises three feeders: one serving a primarily residential area, one industrial feeder serving a small workshop, and one feeder with commercial consumers. The MG consists of different DER units such as the MT, fuel cell and PV. The system data is adopted from Tsikalakis \& Hatziargyriou (2008). It is assumed that all DG sources produce active power at unity power factor, i.e., neither requesting nor producing reactive power. The power factor of all loads is assumed to be equal to 0.85 lagging. Furthermore, there is a power exchange link between the mentioned MG and the utility (LV network) in order to trade energy during a day based on decisions of the MG central controller (MGCC). Load curves of the whole MG for a typical weekday are shown in figure 2.

Table 1 provides the minimum and the maximum operating limits of the DG sources. In the same table, the start-up/shut-down costs, where applicable, are presented. The technical minimum of the MT is obtained from the experiments presented by Yinger (2001), so that its operation is stable for an interconnected operation.

To simplify our analysis, all units in this paper are assumed to be operating in electricity mode only and no heat is required for the examined period.

Table 2 summarizes the costs coefficients assumed by the DG sources expressed in dollars per kilowatt-hour. The evolution of fuel prices is shown in table 3. Actual energy prices from the Amsterdam Power Exchange (ApX http://www.apx.nl) for a day with rather volatile prices have

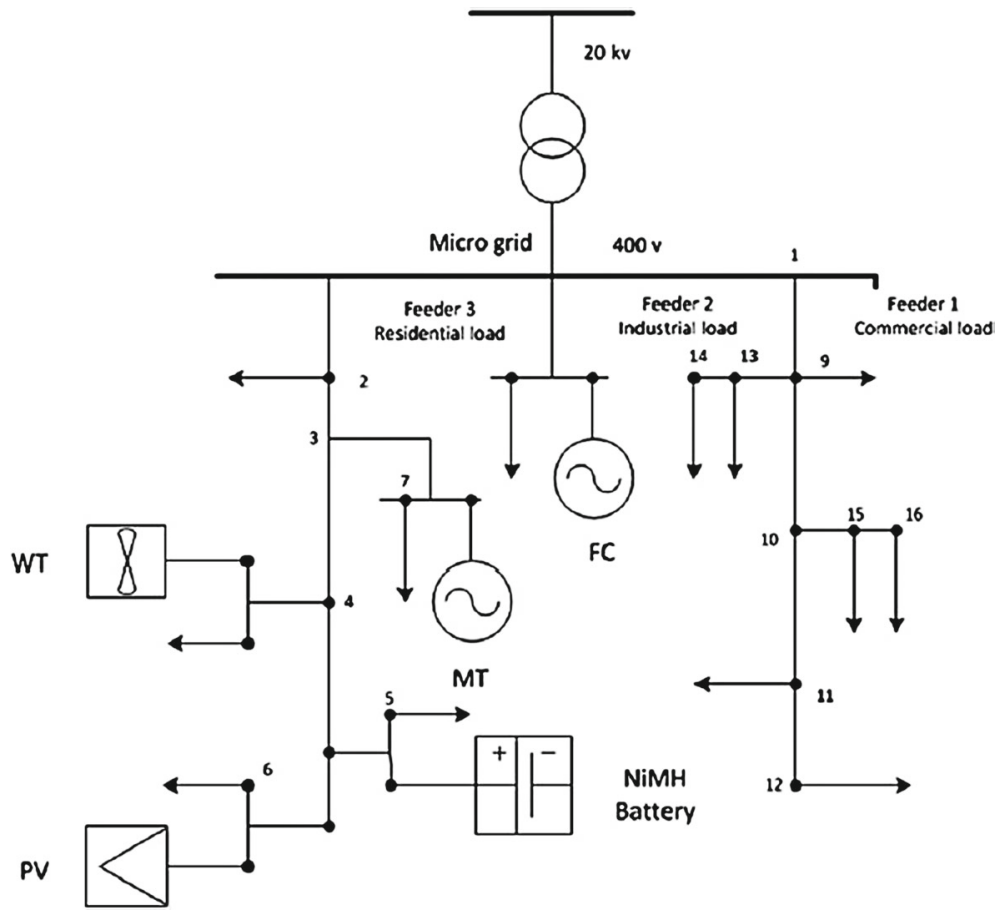

Figure 1. A typical L.V microgrid model. 


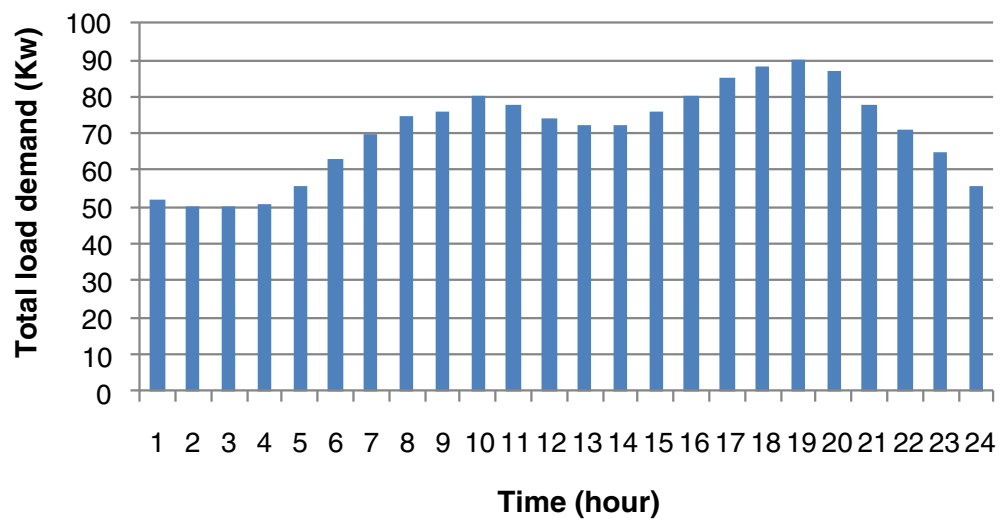

Figure 2. Total forecasted load demand of the whole MG.

been assumed to represent realistically the open market operation (table 4). The MG acts only on the daily market in this paper.

The measured solar irradiance from January 1, 2007 to December 31, 2007 in hourly time scale is obtained from the experiments presented by Changsong et al (2011), which influences the maximum power that the PV arrays could produce under test conditions (figure 3 ). Figure 4 shows the system's hourly power output from January 6 to 10, 2007 recorded in the database of the supervisory control and data acquisition system. According to this figure, it is clear that the output power values of PV system are similar in sunny weather; therefore, PV output (PVO) power can be easily estimated in sunny weather. Figure 5 displays the experimental hourly power data for PV arrays in different weather conditions (Changsong et al 2011). The ratio of the practically PVO in different weather conditions to the estimated one (EO) for clear sky, $\eta=$ $P V O / E O$, has been calculated. Then, we can calculate approximately the PVO power in any weather condition by multiplying the calculated clear sky PVO by the corresponding value of $\eta$ according to the weather forecasting (Jewell \& Unruh 1990).

An ESS installation is studied in the MG. The SBSO finds the optimal sets of power and energy capacities of the storage device by maximization of the NPV in each internal loop.

There are a number of energy storage technologies that have been under development for some time, some of which have been commercialized while others are either in the process of commercialization or are approaching. Now, the selection of the type of storage is also crucial. For energy storage in the high power range for standard power systems, the most suitable ones would be pumped hydro storage, compressed air storage, etc. However, for MGs, where power levels are in the range of a few megawatts, battery is the more suitable option (Haihua et al 2011). Batteries store energy in electrochemical form. Battery technologies differ widely

Table 1. The limits of the installed DG sources.

\begin{tabular}{lccc}
\hline ID & Type & Min power $(\mathrm{kW})$ & Max power $(\mathrm{kW})$ \\
\hline 1 & MT1 & 6 & 30 \\
2 & MT2 & 2 & 20 \\
3 & FC & 3 & 30 \\
4 & PV & 0 & 20 \\
5 & Utility & -30 & 30 \\
\hline
\end{tabular}


Table 2. Costs of the DG sources.

\begin{tabular}{llccc}
\hline & FC & PV & MT1 & MT2 \\
\hline Start-up cost & 0.205 & 0 & 0.115 & 0.156 \\
Fuel cost & 0.036 & 0 & 0.056 & 0.043 \\
Capital cost & 0.109 & 0.702 & 0.036 & 0.121 \\
Replace cost & 0.0130 & 0.084 & 0.004 & 0.016 \\
Operating and management cost & 0.029 & 0.07 & 0.015 & 0.015 \\
\hline
\end{tabular}

in terms of their energy and power densities, cost, cycle-life, availability, and operating conditions (Divya \& Østergaard, 2009; http://www.jmenergy.co.jp/en; http://www.maxwell.com). For example, lead-acid batteries (LAB) are quite inexpensive and have high cycle-life, but they have a low energy density $(25 \mathrm{Wh} / \mathrm{kg}$ ) and require periodic maintenance. In contrast, lithium-ion (Liion) batteries have a very high energy density (90-190 Wh/kg) and a relatively high cycle-life, but are expensive and require advanced circuitry to protect the cells during charging. A compromise solution between LAB and Li-ion batteries is the nickel-metal hydride (NiMH) batteries, which offer a higher energy density and a higher cycle-life in comparison with LAB batteries at a lower price compared with Li-ion batteries. Nickel-cadmium (NiCd) batteries have good characteristics in terms of their cost-to-cycles ratio, but they have two drawbacks; they suffer from 'memory effect' which is a term used to describe the degradation in the battery capacity when it is partly charged and discharged, and they are not environmentally friendly. Sodium sulfur $(\mathrm{NaS})$ and zinc bromine batteries have good characteristics in terms of cost and cycle-life, but these technologies are not fully matured and are not widely available as other batteries. Vanadium Redox Batteries (VRBs) are cost effective and are very robust, but, they have a poor energy density and are not scalable (typically used for very large power applications such as grid applications). In this paper, Simulations are done in two cases using LAB and VRB. Economical and technical data of LAB and VRB are shown in table 5.

As the regulation and optimization capacity of the MG strongly depends on the allocation and arrangement of the energy storage, the classification of ESS power and energy capacities is needed to find global optimization and avoid the local optimized points of ESS. From the

Table 3. Evolution of fuel prices.

\begin{tabular}{lccccccc}
\hline $\begin{array}{l}\text { Time } \\
(\text { week })\end{array}$ & $\begin{array}{c}\text { Fuel price } \\
(\$ / \text { maximum } \$)\end{array}$ & $\begin{array}{c}\text { Time } \\
(\text { week })\end{array}$ & $\begin{array}{c}\text { Fuel price } \\
(\$ / \text { maximum } \$)\end{array}$ & $\begin{array}{c}\text { Time } \\
(\text { week })\end{array}$ & $\begin{array}{c}\text { Fuel price } \\
(\$ / \text { maximum } \$)\end{array}$ & $\begin{array}{c}\text { Time } \\
(\text { week })\end{array}$ & $\begin{array}{c}\text { Fuel price } \\
(\$ / \text { maximum } \$)\end{array}$ \\
\hline 1 & 0.605 & 14 & 0.694 & 27 & 0.76 & 40 & 0.815 \\
2 & 0.55 & 15 & 0.694 & 28 & 0.78 & 41 & 0.817 \\
3 & 0.523 & 16 & 0.675 & 29 & 0.782 & 42 & 0.88 \\
4 & 0.552 & 17 & 0.694 & 30 & 0.77 & 43 & 0.875 \\
5 & 0.575 & 18 & 0.694 & 31 & 0.8 & 44 & 0.925 \\
6 & 0.596 & 19 & 0.675 & 32 & 0.75 & 45 & 0.983 \\
7 & 0.587 & 20 & 0.704 & 33 & 0.75 & 46 & 0.941 \\
8 & 0.589 & 21 & 0.725 & 34 & 0.725 & 47 & 1 \\
9 & 0.623 & 22 & 0.7 & 35 & 0.745 & 48 & 0.959 \\
10 & 0.638 & 23 & 0.726 & 36 & 0.775 & 49 & 0.929 \\
11 & 0.625 & 24 & 0.72 & 37 & 0.81 & 50 & 0.942 \\
12 & 0.624 & 25 & 0.74 & 38 & 0.825 & 51 & 0.95 \\
13 & 0.675 & 26 & 0.738 & 39 & 0.82 & 52 & 0.975 \\
\hline
\end{tabular}


Table 4. Prices from ApX.

\begin{tabular}{lc}
\hline Hour & Price $(\$ / \mathrm{kWh})$ \\
\hline 1 & 0.033 \\
2 & 0.027 \\
3 & 0.020 \\
4 & 0.017 \\
5 & 0.017 \\
6 & 0.029 \\
7 & 0.033 \\
8 & 0.054 \\
9 & 0.215 \\
10 & 0.527 \\
11 & 0.572 \\
12 & 0.572 \\
13 & 0.215 \\
14 & 0.572 \\
15 & 0.286 \\
16 & 0.279 \\
17 & 0.086 \\
18 & 0.059 \\
19 & 0.050 \\
20 & 0.061 \\
21 & 0.181 \\
22 & 0.077 \\
23 & 0.043 \\
24 & 0.037 \\
\hline & \\
\hline
\end{tabular}

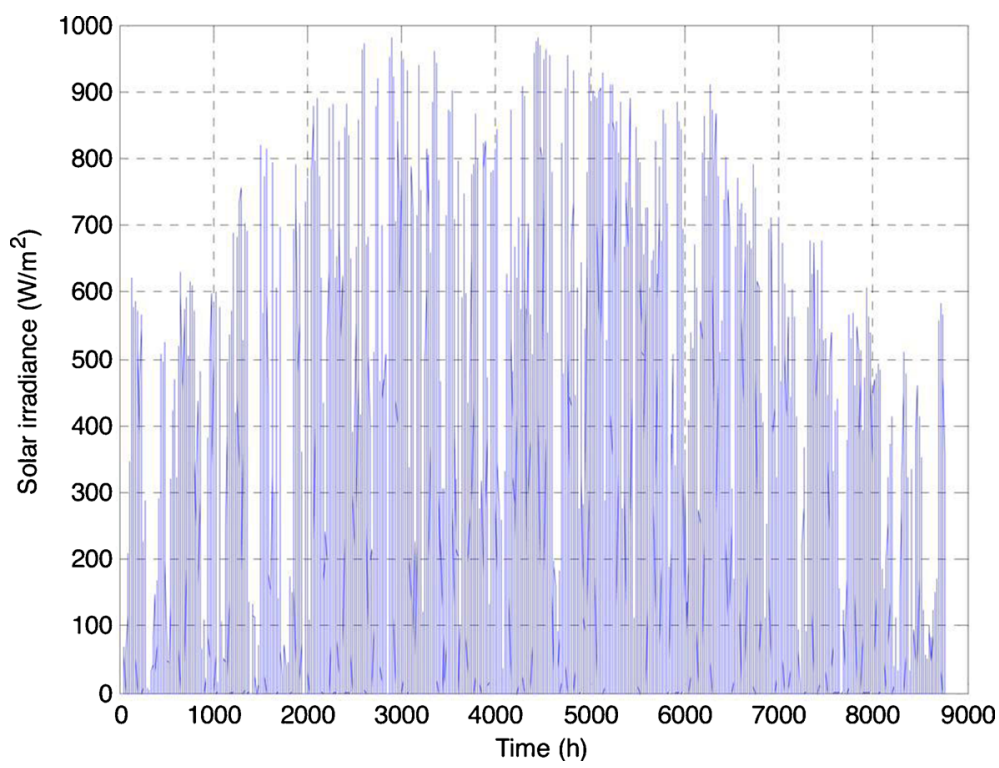

Figure 3. Experimental hourly solar irradiance data during the period January 1-December 31, 2007. 


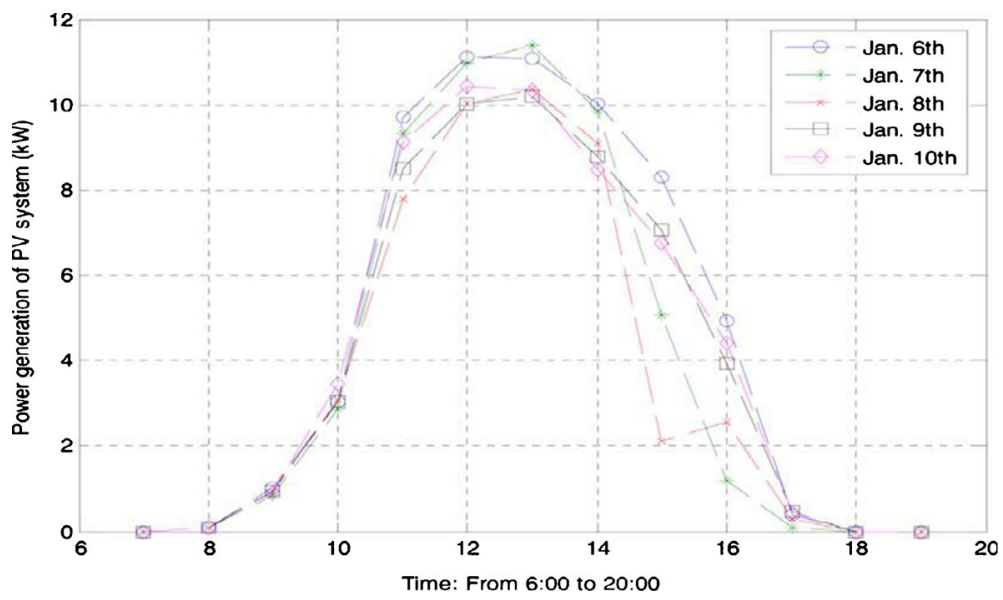

Figure 4. Experimental hourly PV arrays power data during the period January 6-10, 2007.

ESS model applied earlier, there is a proportional relationship between $P_{\max }$ and $C_{\max }$. When the energy capacity of ESS is determined, the power capacity can be set subsequently. Thus, SBSO algorithm can explore global optimized points of ESS, when it is implemented with limited data subsets corresponding to the classification of ESS power and energy capacities. The available range of power and energy capacities are included in table 6 and is divided into 28 subsets. The following procedure is repeated through the chosen $\left(P_{\max }, C_{\max }\right)$ in these subsets. 1) Select a particular pair $\left(P_{\max }, C_{\max }\right)$. 2) Run SBSO algorithm to minimize the operating cost of $\left.\left(P_{\max }, C_{\max }\right) .3\right)$ Select a particular pair $\left(P_{\max }, C_{\max }\right)$.

Tables 7-12 present the results of this optimization in different weather conditions for two cases (LAB and VRB). As shown in these tables, the NPV varies in different weather conditions. Moreover, the NPV of the storage changes with the particular pair $\left(P_{\max }, C_{\max }\right)$. As shown in

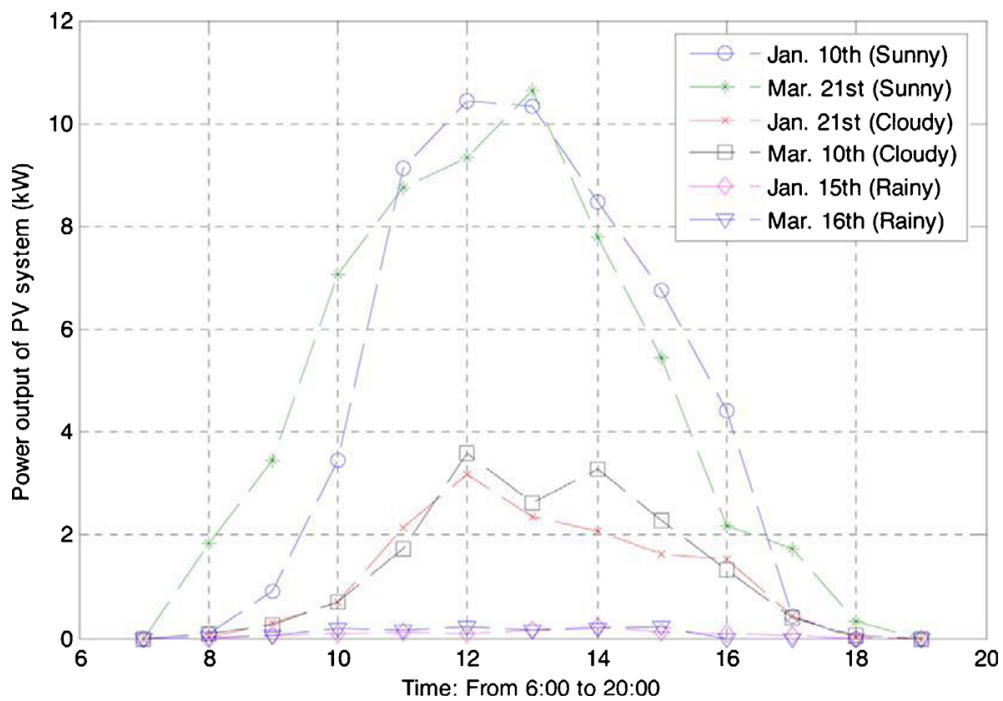

Figure 5. Experimental hourly PV arrays power data recorded by the data logger. 
Table 5. Technical and economical data of VRB and LAB.

\begin{tabular}{lll}
\hline Parameters & $\begin{array}{c}\text { Vanadium redox } \\
\text { battery(VEB) }\end{array}$ & $\begin{array}{c}\text { Lead-acid } \\
\text { battery(LAB) }\end{array}$ \\
\hline$S C_{p}$ & 426 & 0.0 \\
$S C_{W}$ & 100 & 100 \\
Lifespan & 15 & 5 \\
Depth of discharge & 95 & $50 \sim 75$ \\
Efficiency \% & $65 \sim 75$ & 85 \\
Operation cost & 0.0 & 0.02 \\
Discharge energy \% & 2 & 5 \\
\hline
\end{tabular}

Table 6. Classification for power and energy capacities.

\begin{tabular}{|c|c|c|c|c|c|c|c|}
\hline $\mathrm{C}_{\text {Max }}(\mathrm{kWh})$ & & & & $\mathrm{P}_{\text {Max }}($ & & & \\
\hline 10 & $0 \sim 1$ & & & & & & \\
\hline 50 & $0 \sim 1$ & $1 \sim 5$ & & & & & \\
\hline 100 & $0 \sim 1$ & $1 \sim 5$ & $5 \sim 10$ & & & & \\
\hline 200 & $0 \sim 1$ & $1 \sim 5$ & $5 \sim 10$ & $10 \sim 20$ & & & \\
\hline 300 & $0 \sim 1$ & $1 \sim 5$ & $5 \sim 10$ & $10 \sim 20$ & $20 \sim 30$ & & \\
\hline 400 & $0 \sim 1$ & $1 \sim 5$ & $5 \sim 10$ & $10 \sim 20$ & $20 \sim 30$ & $30 \sim 40$ & \\
\hline 500 & $0 \sim 1$ & $1 \sim 5$ & $5 \sim 10$ & $10 \sim 20$ & $20 \sim 30$ & $30 \sim 40$ & $40 \sim 50$ \\
\hline
\end{tabular}

Table 7. Results of the optimization in sunny day (LAB).

\begin{tabular}{|c|c|c|c|c|c|c|c|c|}
\hline \multirow{2}{*}{ NPV } & & \multicolumn{7}{|c|}{$\mathrm{C}_{\text {Max }}(\mathrm{kWh})$} \\
\hline & & 10 & 50 & 100 & 200 & 300 & 400 & 500 \\
\hline \multirow[t]{7}{*}{$\mathrm{P}_{\text {Max }}(\mathrm{kW})$} & $0 \sim 1$ & -3.2345 & -7.4532 & -10.8769 & -17.6810 & -23.987 & -32.5678 & -40.238 \\
\hline & $1 \sim 5$ & & 2.311 & 0.321 & -5.425 & -12.782 & -21.453 & -26.671 \\
\hline & $5 \sim 10$ & & & 10.164 & 7.87 & 1.966 & -4.505 & -15.005 \\
\hline & $10 \sim 20$ & & & & 21.886 & 24.111 & 16.201 & 10.301 \\
\hline & $20 \sim 30$ & & & & & 30.867 & 26.776 & 25.031 \\
\hline & $30 \sim 40$ & & & & & & 28.762 & 27.106 \\
\hline & $40 \sim 50$ & & & & & & & 27.742 \\
\hline
\end{tabular}

Table 8. Results of the optimization in cloudy day (LAB).

\begin{tabular}{|c|c|c|c|c|c|c|c|c|}
\hline \multirow[b]{2}{*}{ NPV } & & \multicolumn{7}{|c|}{$\mathrm{C}_{\text {Max }}(\mathrm{kWh})$} \\
\hline & & 10 & 50 & 100 & 200 & 300 & 400 & 500 \\
\hline \multirow{7}{*}{$\mathrm{P}_{\text {Max }}(\mathrm{kW})$} & $0 \sim 1$ & -8.168 & -11.832 & -15.219 & -22.0315 & -29.687 & -37.856 & -45.323 \\
\hline & $1 \sim 5$ & & -0.2931 & -3.921 & -10.242 & -16.878 & -26.003 & -31.123 \\
\hline & $5 \sim 10$ & & & 6.841 & 4.837 & -0.936 & -7.964 & -19.104 \\
\hline & $10 \sim 20$ & & & & 18.765 & 20.941 & 13.420 & 7.137 \\
\hline & $20 \sim 30$ & & & & & 27.461 & 23.876 & 21.611 \\
\hline & $30 \sim 40$ & & & & & & 25.102 & 24.210 \\
\hline & $40 \sim 50$ & & & & & & & 24.661 \\
\hline
\end{tabular}


Table 9. Results of the optimization in runny day (LAB).

\begin{tabular}{|c|c|c|c|c|c|c|c|c|}
\hline \multirow{2}{*}{\multicolumn{2}{|c|}{ NPV }} & \multicolumn{7}{|c|}{$\mathrm{C}_{\text {Max }}(\mathrm{kWh})$} \\
\hline & & 10 & 50 & 100 & 200 & 300 & 400 & 500 \\
\hline \multirow[t]{7}{*}{$\mathrm{P}_{\text {Max }}(\mathrm{kW})$} & $0 \sim 1$ & -10.068 & -14.502 & -17.119 & -24.115 & -32.371 & -40.019 & -47.132 \\
\hline & $1 \sim 5$ & & -2.521 & -7.891 & -12.222 & -19.118 & -28.303 & -33.971 \\
\hline & $5 \sim 10$ & & & 4.281 & 2.874 & -4.133 & -11.004 & -21.134 \\
\hline & $10 \sim 20$ & & & & 15.876 & 18.998 & 10.893 & 4.937 \\
\hline & $20 \sim 30$ & & & & & 24.889 & 20.816 & 18.915 \\
\hline & $30 \sim 40$ & & & & & & 23.97 & 21.920 \\
\hline & $40 \sim 50$ & & & & & & & 22.764 \\
\hline
\end{tabular}

Table 10. Results of the optimization in sunny day (VRB).

\begin{tabular}{|c|c|c|c|c|c|c|c|c|}
\hline \multirow{2}{*}{ NPV } & & \multicolumn{7}{|c|}{$\mathrm{C}_{\text {Max }}(\mathrm{kWh})$} \\
\hline & & 10 & 50 & 100 & 200 & 300 & 400 & 500 \\
\hline \multirow[t]{7}{*}{$\mathrm{P}_{\text {Max }}(\mathrm{kW})$} & $0 \sim 1$ & -3.234 & -4.365 & -7.527 & -11.341 & -14.681 & -19.742 & -22.566 \\
\hline & $1 \sim 5$ & & 2.947 & 2.453 & 0.763 & -2.453 & -5.126 & -7.342 \\
\hline & $5 \sim 10$ & & & 10.002 & 12.921 & 13.954 & 7.987 & 7.564 \\
\hline & $10 \sim 20$ & & & & 29.131 & 29.461 & 29.311 & 26.971 \\
\hline & $20 \sim 30$ & & & & & 32.431 & 37.824 & 39.41 \\
\hline & $30 \sim 40$ & & & & & & 40.842 & 40.656 \\
\hline & $40 \sim 50$ & & & & & & & 40.431 \\
\hline
\end{tabular}

Table 11. Results of the optimization in cloudy day (VRB).

\begin{tabular}{|c|c|c|c|c|c|c|c|c|}
\hline \multirow[b]{2}{*}{ NPV } & & \multicolumn{7}{|c|}{$\mathrm{C}_{\text {Max }}(\mathrm{kWh})$} \\
\hline & & 10 & 50 & 100 & 200 & 300 & 400 & 500 \\
\hline $\mathrm{P}_{\text {Max }}(\mathrm{kW})$ & $\begin{array}{c}0 \sim 1 \\
1 \sim 5 \\
5 \sim 10 \\
10 \sim 20 \\
20 \sim 30 \\
30 \sim 40 \\
40 \sim 50\end{array}$ & -6.945 & $\begin{array}{l}-7.741 \\
-0.0143\end{array}$ & $\begin{array}{r}-10.651 \\
-1.123 \\
6.011\end{array}$ & $\begin{array}{r}-14.273 \\
-3.256 \\
10.010 \\
26.012\end{array}$ & $\begin{array}{r}-18.104 \\
-6.113 \\
10.342 \\
25.988 \\
29.002\end{array}$ & $\begin{array}{r}-22.903 \\
-8.841 \\
4.365 \\
26.743 \\
35.178 \\
38.002\end{array}$ & $\begin{array}{c}-25.461 \\
-11.238 \\
3.9321 \\
24.171 \\
36.451 \\
37.961 \\
37.241\end{array}$ \\
\hline
\end{tabular}

Table 12. Results of the optimization in runny day (VRB).

\begin{tabular}{|c|c|c|c|c|c|c|c|c|}
\hline \multirow[b]{2}{*}{ NPV } & & \multicolumn{7}{|c|}{$\mathrm{C}_{\text {Max }}(\mathrm{kWh})$} \\
\hline & & 10 & 50 & 100 & 200 & 300 & 400 & 500 \\
\hline $\mathrm{P}_{\text {Max }}(\mathrm{kW})$ & $\begin{array}{c}0 \sim 1 \\
1 \sim 5 \\
5 \sim 10 \\
10 \sim 20 \\
20 \sim 30 \\
30 \sim 40 \\
40 \sim 50\end{array}$ & -8.946 & $\begin{array}{r}-10.162 \\
-3.0231\end{array}$ & $\begin{array}{r}-12.651 \\
-3.642 \\
3.612\end{array}$ & $\begin{array}{r}-17.009 \\
-5.756 \\
6.991 \\
23.143\end{array}$ & $\begin{array}{r}-20.102 \\
-8.312 \\
8.351 \\
23.926 \\
27.002\end{array}$ & $\begin{array}{r}-25.651 \\
-11.238 \\
1.923 \\
23.946 \\
31.965 \\
35.622\end{array}$ & $\begin{array}{r}-27.931 \\
-13.651 \\
1.811 \\
21.722 \\
33.777 \\
35.381 \\
34.611\end{array}$ \\
\hline
\end{tabular}


Table 13. Optimal produces of the MG with the available LAB.

\begin{tabular}{|c|c|c|c|c|c|c|}
\hline \multirow[b]{2}{*}{ Time (Hour) } & \multicolumn{6}{|c|}{ DG Sources (KWh) } \\
\hline & MT1 & FC & PV & MT2 & Battery & Utility \\
\hline 1 & 30 & 2 & 0 & 0 & -15.7850 & 30 \\
\hline 2 & 30 & 30 & 0 & 0 & -17.7850 & 30 \\
\hline 3 & 29 & 30 & 0 & 0 & -17.7850 & 30 \\
\hline 4 & 30 & 30 & 0 & 0 & -16.7850 & 30 \\
\hline 5 & 30 & 30 & 0 & 0 & -11.7850 & 30 \\
\hline 6 & 30 & 30 & 0 & 0 & -3.9150 & 30 \\
\hline 7 & 30 & 30 & 0 & 3 & -2.2150 & 30 \\
\hline 8 & 30 & 30 & 0.2000 & 0 & 20.8499 & 16.6451 \\
\hline 9 & 30 & 30 & 3.7500 & 19.567 & 30 & -19.5350 \\
\hline 10 & 30 & 30 & 7.5250 & 18.234 & 30 & -20.6150 \\
\hline 11 & 30 & 30 & 10.4500 & 17.876 & 30 & -30 \\
\hline 12 & 30 & 30 & 11.9500 & 8.098 & 30 & -30 \\
\hline 13 & 30 & 30 & 12.9000 & 20 & 30 & -30 \\
\hline 14 & 28.56 & 30 & 12.0500 & 20 & 30 & -30 \\
\hline 15 & 28.56 & 30 & 7.8750 & 16.342 & 30 & -23.6600 \\
\hline 16 & 30 & 30 & 4.2250 & 20.765 & 30 & -15.5300 \\
\hline 17 & 29.456 & 30 & 0.5500 & 0 & 0 & -7.3350 \\
\hline 18 & 30 & 30 & 0 & 0 & 0 & 20.2150 \\
\hline 19 & 30 & 30 & 0 & 19.132 & -22.6980 & 30 \\
\hline 20 & 29.432 & 30 & 0 & 0 & 0 & 19.2150 \\
\hline 21 & 25 & 30 & 0 & 0 & 22 & -13.3005 \\
\hline 22 & 30 & 30 & 0 & 0 & -10 & -20.3005 \\
\hline 23 & 30 & 30 & 0 & 0 & -28.9150 & 30 \\
\hline 24 & 20.872 & 30 & 0 & 0 & -26.6150 & 30 \\
\hline
\end{tabular}

Tables 7 and 10 the optimal pairs $\left(P_{\max }, C_{\max }\right)$ of the ESS for two cases in sunny weather are $(30,300)$ and $(40,400)$, respectively. Table 13 shows the optimal produces of the available DG and the LAB technology in sunny weather, where the particular pair $\left(P_{\max }, C_{\max }\right)$ of the ESS is (30, 300). Negative values of ESS in this table are the hourly storage charging of the ESS, whereas positive values indicate storage discharging. Moreover, negative values of utility indicate the excess power of the MG that can be sold to the upstream network, whereas the positive values are the power purchased from the upstream network.

During off-peak hours, the MG purchases cheap power from the upstream network to charge the battery and then consumes the stored power during on-peak periods when utility purchases are relatively expensive. At last, the NPVs have been calculated from the first day to the 365th

Table 14. The one-year NPVs of the MG with LAB.

\begin{tabular}{rcccccccc}
\hline & \multicolumn{7}{c}{$\mathrm{C}_{\text {Max }}(\mathrm{kWh})$} \\
\cline { 2 - 8 } One-year NPV & 10 & 50 & 100 & 200 & 300 & 400 & 500 \\
\hline $\mathrm{P}_{\text {Max }}(\mathrm{kW})$ & $0 \sim 1$ & -2421.5 & -4031.5 & -4930.5 & -7621.7 & -10411 & -13176 & -15641 \\
& $1 \sim 5$ & & 308.45 & -1140.1 & -3235.5 & -5622.7 & -9280.5 & -10982 \\
$5 \sim 10$ & & & 2486 & 1912.3 & -496 & -2765.7 & -6432.8 \\
& $10 \sim 20$ & & & & 6736.1 & 7685.3 & 4896.8 & 2713 \\
$20 \sim 30$ & & & & & 9856 & 8535.5 & 7940 \\
& $30 \sim 40$ & & & & & & 9240.8 & 8826.4 \\
$40 \sim 50$ & & & & & & & 9113 \\
\hline
\end{tabular}


Table 15. The one-year NPVs of the MG with VBR.

\begin{tabular}{|c|c|c|c|c|c|c|c|c|}
\hline \multirow{2}{*}{\multicolumn{2}{|c|}{ One-year NPV }} & \multicolumn{7}{|c|}{$\mathrm{C}_{\operatorname{Max}}(\mathrm{kWh})$} \\
\hline & & 10 & 50 & 100 & 200 & 300 & 400 & 500 \\
\hline \multirow[t]{7}{*}{$\mathrm{P}_{\text {Max }}(\mathrm{kW})$} & $0 \sim 1$ & -2020 & -2513.2 & -3426.9 & -5013.7 & -6029.5 & -8198.4 & -9008.1 \\
\hline & $1 \sim 5$ & & 11.43 & -198.5 & -956.4 & -1813.1 & -2934.1 & -3834.7 \\
\hline & $5 \sim 10$ & & & 2397.2 & 3594.3 & 4098.6 & 1756.8 & 1734.5 \\
\hline & $10 \sim 20$ & & & & 9496.8 & 9794 & 9799.8 & 8964 \\
\hline & $20 \sim 30$ & & & & & 10903 & 12699 & 1376 \\
\hline & $30 \sim 40$ & & & & & & 13620 & 13540.8 \\
\hline & $40 \sim 50$ & & & & & & & 13490 \\
\hline
\end{tabular}

day. Tables 14 and 15 show the one-year NPVs of the MG with LAB and VRB, respectively. The installing LAB and VRB in the MG will produce an optimal one-year NPV of about \$9,856 and $\$ 13,620$, respectively.

\section{Conclusion}

The problem of determining the optimal ESS size and economic analysis of ESS can be solved by the method presented in this paper. The economic viability of the energy storage configuration is explored according to the NPV using SBSO techniques.

The superiority of the method presented in this paper is taking into account the comprehensive design aspects, such as the economical and operational interdependence between various energy storage devices and charge/discharge control systems, the equality constraint of the periodical behaviour, the maximum/minimum storable energy of energy storage installations, the peak power, and the evolution of fuel prices and weather conditions. Furthermore, the proposed optimization method is based on SBSO, in which the ESS power and energy capacities are classified to explore the global optimal solution in different conditions.

The proposed techniques were applied to a typical MG which operates in grid-connected mode. The simulation results show that the optimal sizes, types, and arrangement of the ESSs can be achieved, and the total NPV during the system operational lifetime period is maximized. Moreover, a comparative evaluation between two kinds of battery (VRB and LAB) is performed. Based on the results obtained, VRB is likely to be more cost-effective than LAB according to the one year NPVs.

\section{Nomenclature}

$\begin{array}{ll}p_{i n v_{-} \lim } & \text { Maximum active power output } \\ q_{i n v_{-} \lim } & \text { Maximum reactive power output } \\ S_{\text {inv_lim }} & \text { Inverter capacity } \\ \eta_{D} & \text { Discharging efficiency } \\ \eta_{C} & \text { Charging efficiency } \\ K_{D} & \text { The maximum portion of the rated capacity that can be withdraw from storage } \\ & \text { in an hour } \\ K_{C} & \text { The maximum portion of the rated capacity that can be added to storage in an } \\ & \text { hour }\end{array}$




\begin{tabular}{|c|c|}
\hline$C_{\max }$ & The rated maximum capacity of ESS \\
\hline$C_{\text {min }}$ & The rated minimum capacity of ESS \\
\hline$C(t)$ & The energy stored in the battery bank at hour $t$ \\
\hline$P(t)$ & Electrical power of ESS output at hour $t$ \\
\hline$\Delta t$ & The duration time of each interval \\
\hline$i$ & Interest rate \\
\hline$n$ & The depreciation period in years \\
\hline$k_{i}$ & The capacity factor \\
\hline$T_{a}$ & Operating hours of the year \\
\hline$P_{M}$ & ESS power capacity $(\mathrm{kW})$ \\
\hline$W_{M}$ & ESS energy capacity(kWh) \\
\hline$S C_{p}$ & Specific cost of ESS power $(\$ / \mathrm{kW})$ \\
\hline$S C_{W}$ & Specific cost of ESS energy $(\$ / \mathrm{kWh})$ \\
\hline$S C_{O}$ & Operating specific cost $(\$ / \mathrm{kW})$ \\
\hline$S C_{M}$ & Maintenance specific $\operatorname{cost}(\$ / \mathrm{kWh})$ \\
\hline$l$ & The number of DG \\
\hline$C C_{s}^{D G}$ & The capital cost of $s$ th DG \\
\hline$R_{s}$ & The installed capacity of sth DG \\
\hline$O M_{s}^{D G}$ & Operating and maintenance cost of sth DG \\
\hline$R C_{S}^{D G}$ & The replacement cost of $s$ th DG \\
\hline$R C_{P}$ & The replacement cost of ESS power capacity \\
\hline$R C_{W}$ & The replacement cost of ESS energy capacity \\
\hline$R F_{S}$ & The replacement factor of $s$ th DG \\
\hline$R F^{B A T}$ & The replacement factor of ESS \\
\hline$S_{i}$ & The salvage value of sth DG \\
\hline$S^{B A T}$ & The salvage value of ESS \\
\hline$S F F\left(i, L_{s}^{D G}\right)$ & The sinking fund factor \\
\hline$L_{s}^{D G}$ & The lifetime of sth DG \\
\hline$L^{B A T}$ & The lifetime of ESS \\
\hline$L_{\text {proj }}$ & The lifetime of project \\
\hline$S C_{S}^{D G}$ & The start-up cost of sth DG \\
\hline$N_{s}$ & The number of start-up \\
\hline$F P_{S}^{D G}$ & The fuel price of $s$ th DG on day $d$ (\$/unit fuel) \\
\hline$d$ & The day of year $(1 \leq d \leq 365)$ \\
\hline$A_{s}(t)$ & the fuel utilized by sth DG at hour $t$ \\
\hline$r$ & the number of fuel-consuming DG \\
\hline$E P(t)]$ & The energy price at hour $t(\$ / \mathrm{kWh})$ \\
\hline$E_{s}(t)$ & The energy sell to grid of $s$ th DG \\
\hline$S_{t}$ & The tax rate $(10 \%)$ \\
\hline Iter & Current iteration. \\
\hline$w_{b \min }, w_{b \max }$ & Minimum and maximum values of the cognitive weight factors, respectively. \\
\hline$w_{g \min }, w_{g \max }$ & Minimum and maximum values of the social weight factors, respectively. \\
\hline$N_{\text {swrm }}$ & Total number of the bees in the swarm \\
\hline
\end{tabular}




\section{References}

Abbey C and Joós G 2009 A stochastic optimization approach to rating of energy storage systems in wind-diesel isolated grids. IEEE Trans. Power Syst. 24: 418-426

Agalgaonkar A P, Dobariya C V, Kanabar M G, Khaparde S A and Kulkarni S V 2006 Optimal sizing of distributed generators in microgrid. IEEE Power India Conf 901-908

Akbari R, Mohammadi A and Ziarati K 2010 Novel bee swarm optimization algorithm for numerical function optimization. Commun. Nonlinear Sci. Numer. Simulat. 15: 3142-3155

Ala A H, Nasser K, John Z S and Batarseh I 2012 Distributed battery micro-storage systems design and operation in a deregulated electricity market. IEEE Trans. Sus Energy 3: 545-556

Amsterdam Power Exchange. (2007, Oct. 27). [Online]. Available: http://www.apx.nl

Changsong C, Shanxu D, Tao C, Bangyin L and Guozhen H 2011 Optimal allocation and economic analysis of energy storage system in microgrids. IEEE Trans. Power Syst. 26: 2762-2773

Chen S X, Gooi H B and Wang M Q 2012 Sizing of energy storage for microgrid. IEEE Trans. Smart. Grid. 3: $142-151$

Divya K and Østergaard J 2009 Battery energy storage technology for power systems-An overview. Electr. Power Syst. Res. 79: 511-520

Dukpa A, Dugga I, Venkatesh B and Chang L 2010 Optimal participation and risk mitigation of wind generators in an electricity market. IET Renew. Power Gener. 4: 165-175

Duong T and Ashwin M K 2013 Energy management for lifetime extension of energy storage system in micro-grid applications. IEEE Trans. Smart Grid. 4: 1289-1296

Energy Corp. Datasheets. [Online]. Available: http://www.jmenergy.co.jp/en

Garcia R S and Weisser D 2006 A wind-diesel system with hydrogen storage: Joint optimisation of design and dispatch. Renew. Energy 31: 2296-2320

Haihua Z, Tanmoy B, Duong T, Tuck Sing T S and Ashwin M K 2011 Composite energy storage system involving battery and ultracapacitor with dynamic energy management in microgrid applications. IEEE Trans. Power Elec. 26: 923-930

Jewell W T and Unruh T D 1990 Limits on cloud-induced fluctuation in photovoltaic generation. IEEE Trans. Energy Convers. 5: 8-14

Johanna R and Till R 2011 Subsidies for renewable energies in the presence of learning effects and market power. Resour. Energy Econ. 34: 236-254

Maria Luisa D S, Giorgio G I and Eleonora R S 2014 A Generalized Framework for Optimal Sizing of Distributed Energy Resources in Micro-Grids Using an Indicator-Based Swarm Approach. IEEE Trans. Ind. Inform. 10: 152-162

Marnay C, Venkataramanan G, Stadler M, Siddiqui S, Firestone R and Chandran B 2008 Optimal technology selection and operation of commercial-buildingmicrogrids. IEEE Trans. Power Syst. 23: 975982

Maxwell Corp. datasheets. [Online]. Available: http://www.maxwell.com

Mohammadi S, Mozafari B, Soleymani S, Niknam S and Taher 2013 An adaptive modified firefly optimisation algorithm based on hong's point estimate method to optimal operation management in a microgrid with consideration of uncertainties. Energy 51: 339-348

Mohammadi S, Mozafari B, Soleymani S, Niknam S and Taher 2014a Stochastic scenario-based model and investigating size of energy storages for PEM-fuel cell unit commitment of micro-grid considering profitable strategies. IET GTD doi:10.1049/iet-gtd.2013.0026, 1-16

Mohammadi S, Soleymani S and Mozafari B 2014b Scenario-based stochastic operation management of MicroGrid including Wind, Photovoltaic, Micro-Turbine, Fuel Cell and Energy Storage Devices. Int. J. Electr. Energy 54: 525-535

Poonpun P and Jewell W T 2008 Analysis of the cost per kilowatt hour to store electricity. IEEE Trans. Energy Convers. 23: 529-534

Taylor J, Sharry P and Buizza R 2009 Wind power density forecasting using ensemble predictions and time series models. IEEE Trans. Energy Convers. 24: 775-782 
Tsikalakis A G and Hatziargyriou N D 2008 Centralized control for optimizing microgrids operation. IEEE Trans. Energy Convers. 23: 241-248

Yinger R J 2001 Behavior of Capstone and Honeywell microturbine generators during load changes. Southern California Edison, Rosemad, Tech. Rep. LBNL-49095

Zhen S and Panida J 2014 Optimal operation strategy of energy storage system for grid-connected wind power plants. IEEE Trans. Sustain. Energy 5: 190-199 